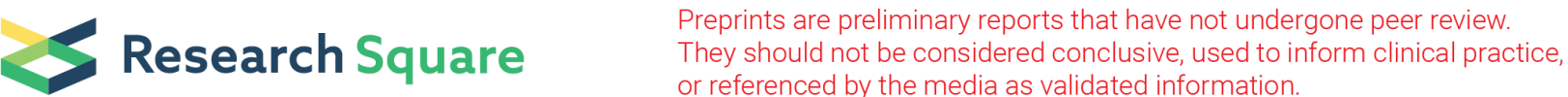

\section{Electronic Reporting of Integrated Disease Surveillance and Response: Lessons learned from Northeast, Nigeria, 2019.}

Luka Mangveep Ibrahim ( $\sim$ ibrahiml@who.int )

World Health Organization

Ifeanyi Okudo

World Health Organization Country Office for Nigeria

Mary Stephen

World Health Organization, African Regional office, Brazzaville, Congo

Opeayo Ogundiran

World Health Organization African Regional Office, Brazzaville, Congo

Jerry Shitta Pantuvo

World Health Organization

Daniel Rasheed Oyaole

World Health Organization

Sisay Gashu Tegegne

World Health Organization

Abdelrahim Khalid

World Health Organization

Elsie llori

Nigeria Center for Disease Control

Olubunmi Ojo

Nigeria Center for Disease Control

Chikwe lhekweazu

Nigeria Center for Disease Control

Fiona Baraka

World Health Organization

Walter Kazadi Mulombo

World Health Organization

Clement Lugala Peter Lasuba

World Health Organization

\section{Peter Nsubuga}

Global public health solutions. Atlanta, GA. USA

Wondimagegnehu Alemu 


\section{Research article}

Keywords: Integrated Disease Surveillance and Response, electronic reporting, elDSR, Nigeria

Posted Date: December 16th, 2020

DOI: https://doi.org/10.21203/rs.3.rs-48119/v2

License: (c) (1) This work is licensed under a Creative Commons Attribution 4.0 International License. Read Full License

Version of Record: A version of this preprint was published at BMC Public Health on May 13th, 2021. See the published version at https://doi.org/10.1186/s12889-021-10957-9. 


\section{Abstract}

Background: Electronic reporting of integrated disease surveillance and response (elDSR) was implemented in Adamawa and Yobe states, North-East of Nigeria, as an innovative strategy to improve disease reporting. Its objectives were to improve the timeliness and completeness of IDSR reporting by health facilities, prompt identification of public health events, timely information sharing, and public health action. We evaluated the project to determine whether it met its set objectives.

Method: We conducted a cross-sectional study to assess and document the lessons learned from the project. We reviewed the performance of the local government areas (LGAs) on timeliness and completeness of reporting, rumors identification, and reporting on the eIDSR and the traditional paperbased system using a checklist. Respondents were interviewed online on the relevance, efficiency, sustainability, project progress and effectiveness, the effectiveness of management, and potential impact and scalability of the strategy using structured questionnaires. Data were cleaned, analyzed, and presented as proportions using an MS Excel spreadsheet. Responses were also presented as direct quotes.

Results: The number of health facilities reporting IDSR increased from 103 to 228 (117\%) before and after implementation of the eIDSR respectively. The timeliness of reporting was $43 \%$ in the LGA compared to $73 \%$ in health facilities implementing eIDSR. The completeness of IDSR reports in the last six months before the evaluation was $\geq 85 \%$. Of the 201 rumors identified and verified, 161 (80\%) were from the eIDSR pilot sites. The majority of the stakeholders interviewed believed that eIDSR met its predetermined objectives for public health surveillance. The benefits of eIDSR included timely reporting and response to alerts and disease outbreaks, improved timeliness, and completeness of reporting, and supportive supervision to the operational levels. The strategy helped stakeholders to appreciate their roles in public health surveillance.

Conclusion: The eIDSR has increased the number of health facilities reporting IDSR, enabled early identification, reporting, and verification of alerts, improved timeliness and completeness of reports, and supportive supervision of staff at the operational levels. It was well accepted by the stakeholder as a system that made reporting easy with the potential to improve the public health surveillance system in Nigeria.

\section{Background}

Public health surveillance remains the cornerstone to overcome health threats affecting humans and their environments globally. The functionality of a surveillance system is gauged by its capacity to prevent outbreaks of disease, detect and report the outbreaks of disease when they occur on time, and promptly respondto contain and control the outbreak [1-3]. An efficient surveillance system is also required to monitor and measure the impact of public health interventions. Its success depends on 
a robust information system with reliable and timely data collection, collation, analysis, interpretation, and transmission of the information for action.

The Integrated Disease Surveillance and Response (IDSR) is the adopted strategy for public health surveillance in Nigeria as with other member states in the African sub-region of the World Health Organization (WHO) [4]. IDSR provides a rational basis for decision-making and implementation of public health interventions that are efficacious in responding to priority diseases and events. The strategy was adopted in Nigeria in 2001 to improve the ability of local government areas (LGAs) to detect and respond to outbreaks of diseases, conditions, and events that cause high levels of mortality, morbidity, and disabilities [5]. It operates at the three levels of governance in the country (National, state, and LGA levels). The health facility (primary, secondary, or tertiary) is the basic operational unit for IDSR. It is the primary point for the generation of surveillance data with the health facility register being the source document. The data from each health facility is collated by the LGA Disease Surveillance and Notification Officer (LGA DSNO) for submission to the State Epidemiologist. Reports from each state are transmitted to the Nigeria Centre for Disease Control (NCDC) at the national level. The process relies on manually extracting the data from a paper-based source at the health facility and transmission to the LGA DSNO. Although the IDSR strategy had been implemented in Nigeria for about two decades [6], delays in detection of diseases such as Lassa fever, measles, cerebrospinal meningitis, and Yellow fever resulting in outbreaks in the country [7-11] highlights problems with the traditional way of implementing the strategy $[12,13]$.

Some countries have utilized information technology (IT) to public health surveillance systems including IDSR. Serra Leon is one of the countries in Africa that had fully digitalized the IDSR reporting system at all level of the health system with promising outcomes $[14,15]$. The speed of information transmission is one of the important qualities of public health surveillance system to prompt public health actions to limit the spread of outbreaks caused by infectious diseases [16-18]. The application of the information technology in public health surveillance facilitates early detection and prompt reporting of disease outbreaks and tracking of response to public health threats [19-21]. The electronic reporting by-passes manual collation improves the quality and reliability of the surveillance data and increases the speed of transmission of the information. Some innovative methods using information technology to improve reporting of diseases and outbreaks in Nigeria include the mobile Strengthening Emergency and Response System (mSERS) and Surveillance Outbreak Response Management and Analysis System (SORMAS). mSERS supports the electronic transmission of the weekly data from the LGA DSNO to the state while SORMAS facilitates automatic notification of outbreaks in real-time by the LGA DSNOs to the higher levels $[19,22]$. These innovative approaches still depend on manual transmission of the IDSR data from the health facilities to the LGA DSNOs. Consequently, there is a need for a system that will boost the performance of disease surveillance and response particularly with early reporting from the health facility level. The eIDSR captures data from the health facilities. The idea was conceived as part of the revitalization of the disease surveillance and response system in the country. Its main goal was to strengthen the disease surveillance system for early detection and real-time reporting enabling prompt response to outbreaks including rumor verification and reporting. 
The objectives were to:

- build capacity of health facility personnel, the LGA, and State on detection, reporting, and response to outbreaks of diseases and public health events in the country

- build the capacity of the LGA and state DSNOs, the state Epidemiologists and national staff on the coordination roles for disease surveillance and management of the surveillance data including the provision of supportive supervision to the lower levels

- improve on the quality of the surveillance data for evidence-based decision making.

- ensure real-time data reporting from the health facility for prompt action

The project was implemented in 10 LGAs from two states in North-East Nigeria. The implementation had a two-phased approach; the first phase was to strengthen the IDSR reporting system at all levels in the selected states. These included the provision of standard case definitions of the priority diseases under surveillance in the country, IDSR reporting tools, and training of the State, LGA and health facility surveillance focal persons on the reporting system. This was based on the premise that introducing a new concept or innovation in a weak system would be worthless. An elDSR can only function in a system where the traditional IDSR system is already working.

The second phase was the introduction of the eIDSR in the selected health facilities. A total of 54 health facilities from 10 LGAs drawn from two states were selected for the initial implementation. The selection criteria were; location of the health facilities, participation in IDSR reporting, availability of the mobile network, accessibility, and good security. An application was developed for the elDSR by a team of specialists on an electronic application for the Auto-visual AFP detection and response (AVADAR) system in the polio eradication initiative. The immediate notification, weekly and monthly reporting forms, as well as supervision checklist, were converted into electronic format. A task team was formed to develop a blueprint and coordinate the implementation of the eIDSR. The members of the task team were also trained on the application which was subsequently field-tested by the task team. Surveillance focal persons and officers in charge of the selected health facilities were trained on the use of mobile phones to collect and report IDSR data. A total of 108 staff from 10 health facilities in the two states to pilot the elDSR. A supervision plan was also developed for the eIDSR. In the plan, the supervisors from States and LGAs were to conduct supportive supervision on the facilities at least once a week using a checklist. The supervision process was to include a written summary of findings, deliberations, and solutions from the health facilities. The states were to produce weekly situation reports and conduct monthly meetings with all stakeholders. There was a quarterly meeting at the national level with all key stakeholders to review the progress of implementation, address challenges, and proffer solutions.

We evaluated the initial implementation of the eIDSR to determine whether the project met its predetermined objectives for improving timeliness and completeness of IDSR reporting, prompt identification of public health events, timely information sharing, and use of the system by the key players in disease surveillance in the piloting facilities and LGAs for actions. 


\section{Methods}

\section{Study design}

We conducted a cross-sectional study to assess and document the lessons learned from the initial implementation of the eIDSR. We reviewed and extracted data on some of the key performance indicators for IDSR implementation at the LGA levels using checklists and interviewed surveillance officers and clinicians on eIDSR using structured questionnaires sent to their mobile phones. Each respondent that consented to participate in the assessment completed the questionnaire and submit online. The questionnaires were adapted from a set of tools for the evaluation of public surveillance systems. Separate tools were developed for respondents at the health facilities and the stakeholders at the LGA and state levels $[23,24]$.

\section{Study setting}

Nigeria has a federal system of government made up of 36 states and a Federal Capital Territory (FCT) with 774 constitutionally recognized local government areas. Yobe and Adamawa states, our study areas are located in the northeastern part of the country. They have an estimated population of 5.5 million people extrapolated from the 2006 national census [25]. The evaluation was conducted in 54 health facilities from 10 LGAs involved in the eIDSR project.

\section{Data collection}

We conducted a desk review of the performance of the LGAs on the reporting of IDSR data. The review included the number of health facilities reporting IDSR before and after the introduction of the eIDSR; the number of rumors identified by the eIDSR system compared to the traditional system; timelines and completeness of weekly IDSR reporting from health facilities implementing eIDSR compared to the traditional system using checklists. The Surveillance focal persons and clinician working at the piloting health facilities, LGA and State DSNO and State Epidemiologist were interviewed online using structured questionnaires on the following six core theme for evaluation of a surveillance system:

(a). The relevance of the strategy: questions were asked on the extent to which the activities designed and implemented were suited to the priorities and realities of the Nigerian context.

(b). Project Progress and Effectiveness: To explore the extent to which the program has adequately achieved its intended outputs and objectives such as prompt identification of public health threats, facilitation of electronic data collection, validation and real-time analysis of data, provisions of a platform for efficient information management and timely information sharing with stakeholders, and generation of accurate weekly aggregate line list of cases.

(c). Sustainability: assessed the ability of supported activities and functions to continue after the program ends 
(d). Effectiveness of Management Arrangements: Explored the extent to which the project brings together relevant stakeholders to achieve project objectives

(e) Potential Impact and Scalability: the likelihood and extent to which the project will contribute to longer-term improvements in the electronic disease early warning system and scale up to the remaining health facilities in the two states in Nigeria.

\section{Data analysis}

Data from the desk review and online evaluation were entered into an MS Excel spreadsheet cleaned, analyzed, and presented as proportions. Responses were also presented as direct quotes.

\section{Ethical considerations}

We obtained ethical clearance for the study from the National Health Research Ethics Committee of Nigeria (NHREC) in the Department of Planning Research and Statistic of the Federal Ministry of Health Nigeria. Informed written consent was also obtained from all respondents involved in the study.

\section{Results}

A total of fifty-two health facilities were involved in the eIDSR pilot, of which 45 (87\%) participated in the evaluation. Forty ( $89 \%)$ were public, and $5(11 \%)$ were private health facilities. The number of health facilities reporting IDSR in the 10 LGAs increased from 103 to 228 (117\%) before and after the implementation of eIDSR respectively. The average timeliness of reporting in the last six months before the evaluation was only $43 \%$ in the piloting LGAs compared to $73 \%$ in health facilities implementing eIDSR. The completeness of reports was $\geq 85 \%$ in the health facilities with elDSR compared to $\leq 65 \%$ in the remaining health facilities in the LGAs (figure 1). Also, of the 201 rumors identified and verified in the 6 months before the evaluation, $161(80 \%)$ were from health facilities with elDSR. A total of 45 staff at the health facilities and 21 stakeholders at the LGA levels responded to the online questionnaire. The respondents at the health facilities were $23(51 \%)$ surveillance focal persons, $13(29 \%)$ officers in charge of the health facilities, 7 (16\%) Assistant DSNOs, and 2 (4\%) Local government area facilitators (LGAFs). Furthermore, of the 21 stakeholders, 11 (52\%) were DSNOs, 5 (24\%) were WHO local government facilitators (WHO LGAF), 3 (14\%) were WHO Cluster coordinators, and 2 (10\%) were AVADAR coordinators.

The respondents reported benefits for surveillance using eIDSR to include timely reporting and prompt response to alert and outbreaks of diseases. The majority of the stakeholders believed that eIDSR met the requirement of public health surveillance. Similarly, all the respondents in the pilot health facilities had received supportive supervision. A third of the respondents asserted that the eIDSR did allow for analysis of the surveillance data at the local level, as many as $42 \%$ mentioned that eIDSR implementation was an added burden to their routine work, and more than a third (38\%) could not sent reports of alerts within two hours of detection (Tables 1 and 2). The perceived central role of the health facility staff in the design of the eIDSR in Nigeria was reporting diseases to a higher level. 
Table 1: eIDSR surveillance attributes from stakeholders' viewpoint $(\mathrm{n}=21)$

\begin{tabular}{|l|l|}
\hline Attributes & $\begin{array}{l}\text { Frequency Yes } \\
(\%)\end{array}$ \\
\hline Do users find eIDSR useful? & $20(95.2)$ \\
\hline Do users find eIDSR simple to use? & $20(95.2)$ \\
\hline Is eIDSR a cost-effective option for Nigeria surveillance system & $20(95.2)$ \\
\hline Do users find eIDSR acceptable? & $18(85.7)$ \\
\hline $\begin{array}{l}\text { Is eIDSR sensitive to identify public health problems at the health } \\
\text { facility level? }\end{array}$ & $21(100)$ \\
\hline $\begin{array}{l}\text { Is eIDSR representative of all public health problems at the health } \\
\text { facility level? }\end{array}$ & $18(85.7)$ \\
\hline Does eIDSR provide timely notifications? & $21(100)$ \\
\hline Is eIDSR stable (or reliable)? & $18(85.7)$ \\
\hline Does eIDSR provide quality data for decision-making? & $20(95.2)$ \\
\hline Is eIDSR flexible (can other diseases be reported through it)? & $19(90.5)$ \\
\hline
\end{tabular}

Table 2: View of respondents on the design and implementation of eIDSR

\begin{tabular}{|c|c|c|c|c|}
\hline Theme & Queries & $\begin{array}{l}\text { Yes } \\
(\%)\end{array}$ & $\begin{array}{l}\text { No } \\
(\%)\end{array}$ & Total \\
\hline \multirow[t]{4}{*}{$\begin{array}{l}\text { The relevance of the } \\
\text { eIDSR }\end{array}$} & $\begin{array}{l}\text { eIDSR designed according to Nigerian } \\
\text { Context }\end{array}$ & $\begin{array}{l}45 \\
(100)\end{array}$ & $(0)$ & 45 \\
\hline & Staff trained before implementation of eIDSR & $\begin{array}{l}44 \\
(98)\end{array}$ & $\begin{array}{ll}1 \\
(2)\end{array}$ & 45 \\
\hline & $\begin{array}{l}\text { Staff received supportive supervision during } \\
\text { implementation of eIDSR }\end{array}$ & $\begin{array}{l}42 \\
(93)\end{array}$ & $\begin{array}{l}3 \\
(7)\end{array}$ & 45 \\
\hline & eIDSR suitable for health facilities reporting & $\begin{array}{l}20 \\
(95)\end{array}$ & $\begin{array}{ll}1 \\
(5)\end{array}$ & 21 \\
\hline \multirow[t]{6}{*}{$\begin{array}{l}\text { Project progress and } \\
\text { effectiveness }\end{array}$} & $\begin{array}{l}\text { Alert detected in the last three months by the } \\
\text { system }\end{array}$ & $\begin{array}{l}25 \\
(56)\end{array}$ & $\begin{array}{l}20 \\
(44)\end{array}$ & 45 \\
\hline & $\begin{array}{l}\text { The time lag of two hours or less between } \\
\text { detection and reporting of alerts }\end{array}$ & $\begin{array}{l}28 \\
(62)\end{array}$ & $\begin{array}{l}17 \\
(38)\end{array}$ & 45 \\
\hline & eIDSR data analyzed at the local levels & $\begin{array}{l}7 \\
(33)\end{array}$ & $\begin{array}{l}14 \\
(67)\end{array}$ & 21 \\
\hline & $\begin{array}{l}\text { eIDSR used for action at the health facility } \\
\text { levels }\end{array}$ & $\begin{array}{l}44 \\
(98)\end{array}$ & $\begin{array}{ll}1 \\
(2)\end{array}$ & 45 \\
\hline & $\begin{array}{l}\text { Implementation of eIDSR added burden to the } \\
\text { work of the staff }\end{array}$ & $\begin{array}{l}19 \\
(42)\end{array}$ & $\begin{array}{l}26 \\
(58)\end{array}$ & 45 \\
\hline & $\begin{array}{l}\text { eIDSR is a cost-effective option for public } \\
\text { health surveillance in Nigeria }\end{array}$ & $\begin{array}{l}20 \\
(95)\end{array}$ & $\begin{array}{ll}1 \\
(5)\end{array}$ & 21 \\
\hline \multirow[t]{2}{*}{ Efficiency } & $\begin{array}{l}\text { eIDSR reflects the efforts staff put into the } \\
\text { surveillance system }\end{array}$ & $\begin{array}{l}16 \\
(76)\end{array}$ & $\begin{array}{ll}5 \\
(24)\end{array}$ & 21 \\
\hline & $\begin{array}{l}\text { The system will contribute to e-surveillance in } \\
\text { the long term }\end{array}$ & $\begin{array}{l}21 \\
(100)\end{array}$ & $\begin{array}{ll}0 \\
(0)\end{array}$ & 21 \\
\hline
\end{tabular}

Deductions from the respondents were as follows; 
- elDSR has demonstrated the need and feasibility for an electronic solution for event-based and possibly indicator-based surveillance and response in Nigeria, which is the basis for eSurveillance.

- It was easy to use at the health facility level.

- eIDSR provided regular data updates to higher levels.

- elDSR was capable of sending alerts within 2 hours of detection and had been used to send alerts from health facilities in several instances over the past 3 months.

- elDSR was found to be useful at all levels, particularly in providing timely alerts of public health conditions.

- elDSR had demonstrated the importance of mobile technology in event-based reporting (Table 3).

Table 3: Some direct quotes from respondents on the design and implementation of the eIDSR 


\begin{tabular}{|c|c|}
\hline Theme & Comments/quotes from respondents \\
\hline \multirow{3}{*}{$\begin{array}{l}\text { DSNO/State } \\
\text { epidemiologists views } \\
\text { on the extent to which } \\
\text { eIDSR achieved its } \\
\text { objectives }\end{array}$} & $\begin{array}{l}\text { It improves the knowledge gap of health workers, through } \\
\text { training, supervision, and on-the-job training. }\end{array}$ \\
\hline & $\begin{array}{l}\text { Immediate notifications and actions were taken on diseases and } \\
\text { conditions of public health concerns at the grassroots level. }\end{array}$ \\
\hline & $\begin{array}{l}\text { It improved the disease surveillance system, increase the flow } \\
\text { of data, and improve the early detection and investigation of } \\
\text { diseases and conditions of public health concerns. }\end{array}$ \\
\hline \multirow[t]{3}{*}{$\begin{array}{l}\text { Surveillance focal } \\
\text { person views on the } \\
\text { major achievements of } \\
\text { eIDSR in Nigeria }\end{array}$} & $\begin{array}{l}\text { It helped in the instant notification of cases that led to the } \\
\text { investigation and appropriate public health interventions. More } \\
\text { so, it brought line managers closer to surveillance happening at } \\
\text { the peripheral level. }\end{array}$ \\
\hline & $\begin{array}{l}\text { The major achievements included the illustration of how mobile } \\
\text { technology can be used to report alerts of IDSR cases, data } \\
\text { collection can occur at facilities and be readily available at all } \\
\text { level, and dashboards for the ministry of health }\end{array}$ \\
\hline & $\begin{array}{l}\text { It can be used to show data in real-time, and alerts can be } \\
\text { generated to inform the leadership of potential disease } \\
\text { outbreaks. }\end{array}$ \\
\hline \multirow{3}{*}{$\begin{array}{l}\text { DSNO/State } \\
\text { epidemiologists views } \\
\text { on the ability to roll out } \\
\text { eIDSR }\end{array}$} & It helps in reduction in the printing of data tools \\
\hline & It reduces the cost of paper or written materials to do the job. \\
\hline & $\begin{array}{l}\text { Surveillance data will be easily accessed with eIDSR than the } \\
\text { traditional method of reporting. Data reported through the } \\
\text { traditional system can be altered along the channel of reporting } \\
\text { due to manual compilation }\end{array}$ \\
\hline \multirow{3}{*}{$\begin{array}{l}\text { Surveillance focal } \\
\text { person views on how } \\
\text { using eIDSR have } \\
\text { benefited their state } \\
\text { and Nigeria }\end{array}$} & $\begin{array}{l}\text { It has contributed a lot in identifying and reporting priority } \\
\text { diseases and other conditions of public health concern to the } \\
\text { responsible authorities, for prompt intervention }\end{array}$ \\
\hline & $\begin{array}{l}\text { eIDSR contributed to public health surveillance and response in } \\
\text { the community }\end{array}$ \\
\hline & $\begin{array}{l}\text { It makes it easier to report priority diseases timely and } \\
\text { completely for prompt action }\end{array}$ \\
\hline \multirow{4}{*}{$\begin{array}{l}\text { DSNO/State } \\
\text { epidemiologists view on } \\
\text { the output of eIDSR } \\
\text { relative to the effort put } \\
\text { in it }\end{array}$} & It improved timely reporting and eliminate missing reports \\
\hline & $\begin{array}{l}\text { It keeps the LGA and state informed about immediately } \\
\text { reportable diseases }\end{array}$ \\
\hline & $\begin{array}{l}\text { The system prompted me to verify cases from sources before } \\
\text { sending them to a higher level for action }\end{array}$ \\
\hline & $\begin{array}{l}\text { The system helped me to participate more actively in } \\
\text { surveillance activities in my LGA }\end{array}$ \\
\hline \multirow{3}{*}{$\begin{array}{l}\text { How eIDSR could } \\
\text { contribute to public } \\
\text { health surveillance in } \\
\text { Nigeria }\end{array}$} & It helped to improved reporting and response. \\
\hline & $\begin{array}{l}\text { eIDSR has made reporting easier. Therefore, in the future, it } \\
\text { will contribute greatly to surveillance such that diseases will be } \\
\text { reported immediately for action. }\end{array}$ \\
\hline & $\begin{array}{l}\text { It will help the country report on time outbreaks and other } \\
\text { conditions of public health concerns in the communities. It also } \\
\text { helped prompt the detection of cases that came from the } \\
\text { community. }\end{array}$ \\
\hline
\end{tabular}

\section{Discussion}

The evaluation of the eIDSR implementation revealed that the strategy contributed significantly to improving the operation of the integrated disease surveillance and response in the states. The major contributions were on the numerical increase in health facilities involved in reporting and the key 
performance indicators for IDSR. The increase in health facilities reporting IDSR in the piloting LGAs might have been due to refresher training to the surveillance officers at the state and LGA levels. The training built the capacity of the surveillance officers to be more responsive to support the surveillance focal persons at the health facility level through regular supplies of the data collection and reporting tools, verification of alerts, supportive supervision, and feedbacks. Strengthening of the existing system should be one of the essential consideration before the introduction of a new strategy. Furthermore, a system can only operate well if the basic support functions are in place. The support for the elDSR implementation included training, provision of case definitions, reporting tools, and android phones. Training is one of the indispensable strategies to strengthen a system to introduce electronic reporting of the IDSR. This is corroborated by the findings of Njeru I et al from Kenya. They expounded on the importance of training on the use of technology in improving public health surveillance reporting [26]. Moreover, experiences shared from Uganda among participants at a focus group discussion showed that training on IDSR at operational levels led to the improvement in the completeness and timeliness of reporting, case detection, and data analysis [27, 28]. Timeliness and completeness are two critical complementary performance indicators of the IDSR strategy. Timely reporting of diseases especially communicable diseases is crucial to the initiation of public health actions to prevent transmission leading to large outbreaks. In the traditional method of using paper-based reporting, reports are delayed because it depends on the physical transmission of the report from the health facilities to the LGA. Electronic reporting increased the speed of transmission of the report from the health facilities to the DSNOs at the LGA and state levels [29]. This is supported by the finding of Rebecca Wurtz and Bruce J. Cameron on electronic laboratory reporting (ELR). In their report, ELR increased the speed of completeness of the reporting $[30,31]$. Completeness of reporting in our context is not disease-specific or case enumeration, [32] but is based on the number of health facilities sending IDSR reports to the next level within agreed deadlines $[5,33]$. Putting the timeliness and completeness together, the generation of information products for decision making to limit mortality and morbidity from any unexpected health event depends on the speed of detection, reporting, and completeness of the data. Our pilot project revealed an increase in these key performance indicators of the IDSR. The finding from our pilot is corroborated by Randriamiarana R et al. from Madagascar [34], who noted that short message services (SMS) improved the completeness and quality of IDSR data. Although the electronic system of reporting such as the mobile Strengthening Emergency and Response System (mSERS) and the Surveillance Outbreak Response Management and Analysis System (SORMAS) are operational in the country [35], both systems are stationed at the LGA levels and depend on the paper-based reporting from health facility level leading to delays in reporting. The electronic reporting system stationed at operational levels (health facilities) increased the speed of reporting and by-passed the manual collation at the LGA thereby improving the quality of the data. The result also revealed that the electronic transmission of data from health facilities improved the detection, reporting, and verification of alerts which is one of the major lifesaving precursors of public health surveillance.

Although there is paucity of information on the electronic IDSR because it was newly introduced in the country, the views of our respondents have revealed that the system was good and improved their work 
although significant proportion (42\%) were of the view that it was an added burden to their routine work. This views might be the results of inadequate personnel in many of the rural health facilities in Nigeria. Their viewpoint assertion is supported by the findings of Soto $\mathrm{G}$ et al, from an evaluation of a four-year implementation of an electronic disease surveillance system in a resource-limited setting. The Authors noted personnel issues as one of the major challenges of implementing the system in resource limited setting. Other challenges reported by the Authors included lack of access to internet services and mobile phones were some of the major challenges of the electronic surveillance system [36]. The personal benefits from the use of the phone might have contributed to the observed variance. In our pilot, the free mobile phones were part of the support to participants, and the surveillance focal persons were at liberty to use phones for private communications and other social activities. Additionally, the personal benefits could have been a motivating factor for the users to ensure their phones remained functional at all times.

The results of our pilot showed that there was an improvement in the level of supportive supervision to the operational level. The use of ODK for the supervision might have contributed to the improvement because each site visited was recorded and transmitted in real-time to higher levels. The importance of supportive supervision cannot be overemphasized, as this is the basic element for the improvement of work performance through watching, directing, and guiding what the individual is doing or how a task should be done. The ultimate aim of supervision is to sustain good quality services, identify problems, decide what has caused a problem, and develop feasible solutions. The additional training for the supervisors might have contributed to improving their work performance and commitment.

The evaluation approach had some limitations. Firstly, all the respondents were participants in the pilot and could have views that were influenced by their role in the program. There may have been a natural bias to focus on the program successes, although the team tried to tease out other critical points to the questions. Secondly, we envisage recall bias as one of the major limitations because the evaluation questions required the respondents to have adequate recall of events that occurred in the past but we tried to triangulate sources of information to limit its effect.

\section{Conclusion}

The evaluation of the eIDSR project in the two states has revealed that the system had a positive impact on the key performance indicators for IDSR, improved supportive supervision of the staff at operational levels including data transmission, and information sharing. The innovation was well accepted by stakeholders and viewed by the frontline surveillance officers and health workers as a system that made reporting in public surveillance easy. The innovation if well harnessed will bring a paradigm shift in public health surveillance in Nigeria.

\section{List Of Abbreviations}

DSNO: Disease surveillance and notification officer 
eIDSR: Electronic Integrated Disease Surveillance and Response

ELR: Electronic Laboratory Reporting

FCT: Federal capital territory

IDSR: Integrated disease surveillance and response

ICT: Information communication technology

IT: Information technology

LGA: Local government area

LGA DSNO: Local government disease surveillance and notification officer

LGAF: Local government facilitators

mSERS: mobile Strengthening Emergency and Response System (mSERS)

MS: Microsoft

NCDC: Nigeria center for disease control

NHREC: National Health Research Ethics Committee of Nigeria

ODK: Open Data Kit

SORMAS: Surveillance Outbreak Response Management and Analysis System

SMS: Short Message Services

SDSNO: State disease surveillance and notification officer

WHO: World health organization

\section{Declarations}

\section{Ethical approval}

Ethical approval for the evaluation was obtained from the National Health Research Ethics Committee of Nigeria (NHREC) in the Department of Planning Research and Statistic of the federal ministry of health Nigeria, reference number NHREC/01/01/2007-03/03/2020

\section{Consent for publication}

Not applicable in this survey 
Availability of data and materials

The dataset used and analyzed during this study are available from the corresponding author on reasonable request

\section{Competing interest}

The authors declare that they have no competing interest

\section{Funding}

None

\section{Authors contributions}

PN Conception, design, and writing of protocol for the evaluation, acquisition of data, analysis, and interpretation of data, and critical review of the manuscript. LMI Design, acquisition of data, analysis, interpretation of the evaluation data and wrote the manuscript. JSP Acquisition of data and literature review. IO, MS, AK, El, OO, Cl, OO, DRO, SGT, FB, and WKM, Literature review, and review of the manuscripts. CLPL and WA Critical review and approved the final manuscript.

All the authors have read and approved the final version of the manuscript

\section{Acknowledgment}

We want to acknowledge the disease surveillance focal persons in the piloted health facilities, the officers in charge of the health, and the coordinators of primary health care services in the LGAs their supports in the course of carrying out the study.

\section{References}

1. International Health regulations (2005). Third edition. World Health Organization, 20 Avenue Appia, 1211 Geneva 27, Switzerland

2. Nsubuga P, Nwanyanwu O, Nkengasong J. N, Mukanga D, Trostle M. Strengthening public health surveillance and response using the health systems strengthening agenda in developing countries. BMC Public Health 2010, 10(Suppl 1): S5 http://www.biomedcentral.com/1471-2458/10/S1/S

3. Wolicki SB, Nuzzo JB, Blazes DL, Pitts DL, Iskander JK, Tappero JW. Public Health Surveillance: At the Core of the Global Health Security Agenda. Health Secur. 2016;14(3):185-188. doi:10.1089/hs.2016.0002

4. WHO/AFRO IDSR Guidelines 2013. World Health Organization, 20 Avenue Appia, 1211 Geneva 27, Switzerland

5. Technical Guidelines for Integrated Disease Surveillance and Response in Nigeria. March 2013 
6. National Policy on Integrated Disease Surveillance and Response (IDSR) Federal Ministry of Health. Abuja, Nigeria. September 2005.1

7. NCDC, Weekly epidemiological report, Nigeria center for disease control. https://ncdc.gov.ng/reports/167/2018-december-week-52 accessed 19/9/2019

8. Adebimpe W O. Pre-epidemic preparedness and the control of Lassa fever in Southern Nigeria. Res. J. of Health Sci. 2016:4(3);243-254

9. Ibrahim BS, Usman R, Mohammed Y, Datti Z, Okunromade O, Abubakar A, Nguku P M.Burden of measles in Nigeria: a five-year review of case-based surveillance data, 2012-2016. The Pan African Medical Journal. 2019;32 (Supp1):5. doi:10.11604/pamj.supp.2019.32.1.13564

10. NCDC, Situation report, cerebrospinal meningitis outbreak in Nigeria, January 2018. ncdc.gov.ng. accessed $30^{\text {th }}$ January 2019

11. NCDC, situation report, yellow fever outbreak in Nigeria 2017, $5^{\text {th }}$ December 2018. ncdc.gov.ng. Accessed $30^{\text {th }}$ January 2019

12. Hassan A, Mustapha GU, Lawal BB, Na'uzo AM, Ismail R, Womi-Eteng Oboma E, et al. (2018) Time delays in the response to the Neisseria meningitidis serogroup C outbreak in Nigeria - 2017. PLoS ONE 13(6): e0199257. https://doi.org/10.1371/journal.pone.0199257

13. Daniel W. Martin, Michelle L Sloan, Brigette L. Gleason, Les de Wit, Mohamed Alex Vandi, Daivid K. Kargbo, Nelson Clemens, Asumana Kamara, Charles Njuguna, Stephen Sesay, and Tushar Singh. Health Security. Jan 2020. S-72-S-80. http://doi.org/10.1089/hs.2019.008

14. Bagherian H, Farahbakhsh M, Rabiei R, Moghaddasi H, Asadi F. National Communicable Disease Surveillance System: A review on Information and Organizational Structures in Developed Countries. Acta Inform Med. 2017;25(4):271-276. doi:10.5455/aim.2017.25.271-276

15. Omoleke SA, Ajibola O, Ajiboye JO, et al. Quagmire of epidemic disease outbreaks reporting in Nigeria. BMJ Glob Health 2018;3: e000659. doi:10.1136/ bmjgh-2017-000659

16. Chaudhry B, Wang J, Wu S, Wu S, Maglione M, Mojica W, Roth E, Morton SC, Shekelle P G. Systematic review: impact of health information technology on quality, efficiency, and costs of medical care. Ann Intern Med. 2006;144(10):742-752. doi:10.7326/0003-4819-144-10-20060516000125

17. Kant, L., Krishnan, S.K. Information, and communication technology in disease surveillance, India: a case study. BMC Public Health10, S11 (2010). https://doi.org/10.1186/1471-2458-10-S1-S11

18. Chandrasekar K. Use of Information Communication Technology in communicable disease surveillance. Sri Lanka Journal of Bio-Medical Informatics 2011;2(2):41-52 DOI: http://dx.doi.org/10.4038/sljbmi.v2i2.3541

19. Rajesh Kumar Sinha. Impact of Health Information Technology in Public Health Sri Lanka Journal of Bio-Medical Informatics 2010;1(4):223-36 DOI: 10.4038/sljbmi. v1i4.2239

20. Diwan $V$, Agnihotri $D$, and Hulth A. Collecting syndromic surveillance data by mobile phone in rural India: implementation and feasibility. Glob Health Action 2015, 8: 26608 - 
http://dx.doi.org/10.3402/gha.v8.26608

21. Sawesi S, Rashrash M, Phalakornkule K, Carpenter JS, Jones JF. The Impact of Information Technology on Patient Engagement and Health Behavior Change: A Systematic Review of the Literature. Eysenbach G, ed. JMIR Medical Informatics. 2016;4(1): e1. doi:10.2196/medinform.4514.

22. Technical Guidelines for Integrated Disease Surveillance and Response in Nigeria. 2019

23. WHO: Evaluating a national surveillance system. 2013, World Health Organization Department of HIV/AIDS, Avenue Appia 201211 Geneva 27 Switzerland www. who. int/hiv

24. Klaucke D N., Buehler J W., Thacker S B., Parrish R. G., M.D. Trowbridge F L., Berkelman R L. Guidelines for Evaluating Surveillance Systems.1988. MMWR 37(S-5); 1-18

25. Demographic statistics Bulletin - National Bureau of Statistics, 2017. Nigeria. https://nigeriastat.gov.ng/download/775 Accessed 02/02/2020

26. Njeru, I., Kareko, D., Kisangau, N. et al. Use of technology for public health surveillance reporting: opportunities, challenges, and lessons learned from Kenya. BMC Public Health20, 1101 (2020). https://doi.org/10.1186/s12889-020-09222-2

27. Nakiire L., Masiira B., Kihembo C., Katushabe E., Natseri N., Nabukenya I., Komakech I., Makumbi I., Charles O., Adatu F., Nanyunja M., Nsubuga P., Woldetsadik S. F., Tusiime P., Yahaya A. A., Fall I. S., Wondimagegnehu A. Healthcare workers' experiences regarding scaling up of training on integrated disease surveillance and response (IDSR) in Uganda, 2016: a cross-sectional qualitative study. BMC Health Services Research (2019) 19:117. https://doi.org/10.1186/s12913-019-3923-6

28. Masiira B., Nakiire L., Kihembo C., Katushabe E., Natseri N., Nabukenya I., Komakech I., Makumbi I., Charles O., Adatu F., Nanyunja M., Woldetsadik S. F., Fall I. S., Tusiime P., Wondimagegnehu A., Nsubuga P. Evaluation of integrated disease surveillance and response (IDSR) core and support functions after the revitalization of IDSR in Uganda from 2012 to 2016. BMC Public Health (2019) 19:46. https://doi.org/10.1186/s12889-018-6336-2

29. Reijn E., Swaan C.M., Kretzschmar M.E., Steenbergen J.E. Analysis of timeliness of infectious disease reporting in the Netherlands. BMC Public Health 11, 409 (2011) doi:10.1186/1471-2458-11-409.

30. Rebecca Wurtz, Bruce J. Cameron, Electronic Laboratory Reporting for the Infectious Diseases Physician and Clinical Microbiologist, Clinical Infectious Diseases, Volume 40, Issue 11, 1 June 2005, Pages 1638-1643, https://doi.org/10.1086/429904

31. Swaan C, van den Broek A, Kretzschmar M, Richardus JH. Timeliness of notification systems for infectious diseases: A systematic literature review. PLoS One. 2018;13(6): e0198845. Published 2018 Jun 14. doi: 10.1371/journal.pone.0198845

32. Timothy J. Doyle, M. Kathleen Glynn, Samuel L. Groseclose, Completeness of Notifiable Infectious Disease Reporting in the United States: An Analytical Literature Review, American Journal of Epidemiology, Volume 155, Issue 9, 1 May 2002, Pages 866-874, https://doi.org/10.1093/aje/155.9.866

33. WHO/AFRO IDSR Technical Guidelines $3^{\text {rd }}$ Edition, 2019. World Health Organization, 20 Avenue Appia, 1211 Geneva 27, Switzerland 
34. Randriamiarana R, Raminosoa G, Vonjitsara N, Randrianasolo R, Rasamoelina H, Razafimandimby H, Rakotonjanabelo A L, Lepec R, Flachet L, Halm A. Evaluation of the reinforced integrated disease surveillance and response strategy using short message service data transmission in two southern regions of Madagascar, 2014-15. BMC Health Services Research (2018) 18:265 https://doi.org/10.1186/s12913-018-3081-2

35. Chandrasekar K. Use of Information Communication Technology in communicable disease surveillance. Sri Lanka Journal of Bio-Medical Informatics 2011;2(2):41-52 DOI: http://dx.doi.org/10.4038/sljbmi.v2i2.3541

36. Soto G., Araujo-Castillo R V., Neyra J., Fernandez M., Leturia C., Mundaca C. C., Blazes D. L. Challenges in the implementation of an electronic surveillance system in a resource-limited setting: Alerta, in Peru. BMC Proceedings 2008, 2(Suppl 3): S4

\section{Figures}

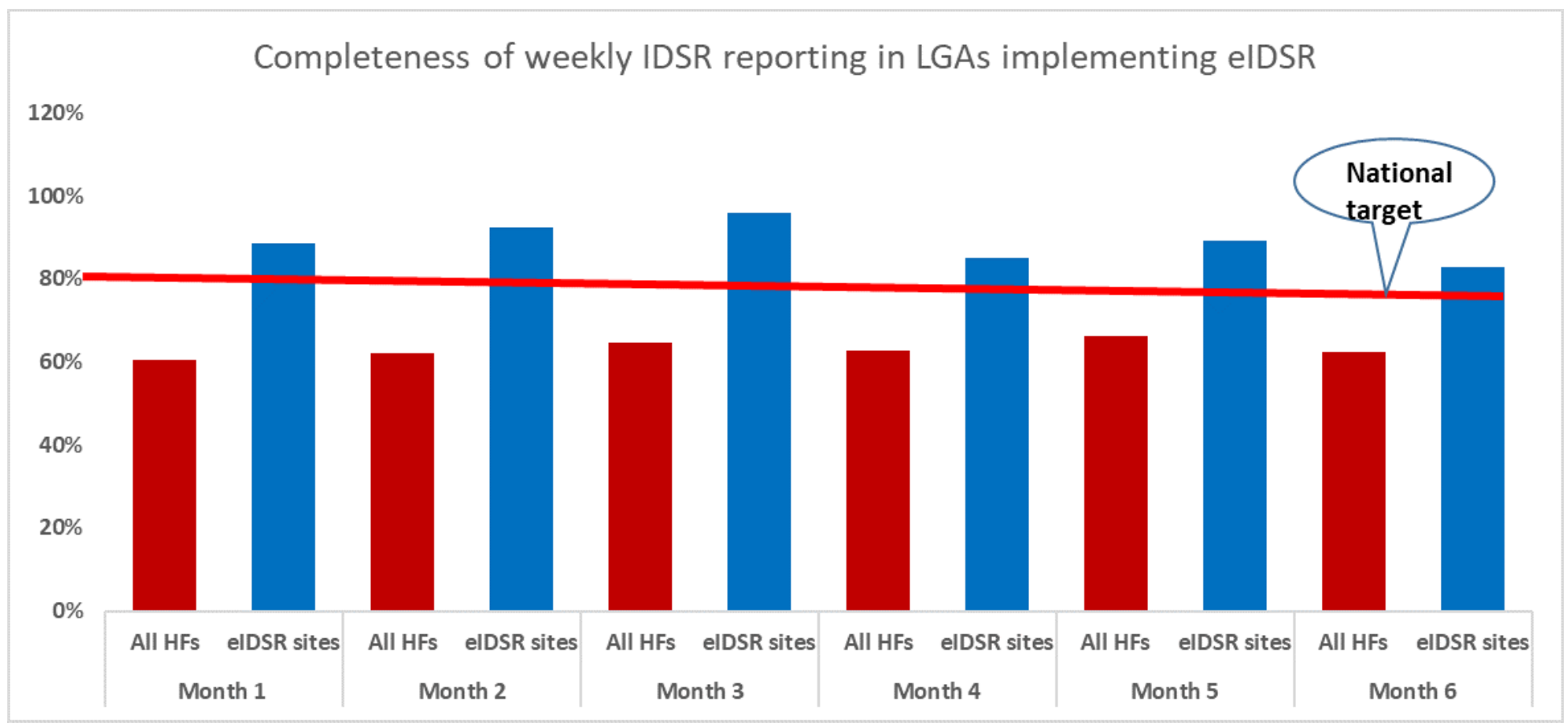

Figure 1

Completeness of weekly IDSR reporting in all and health facilities with eIDSR 


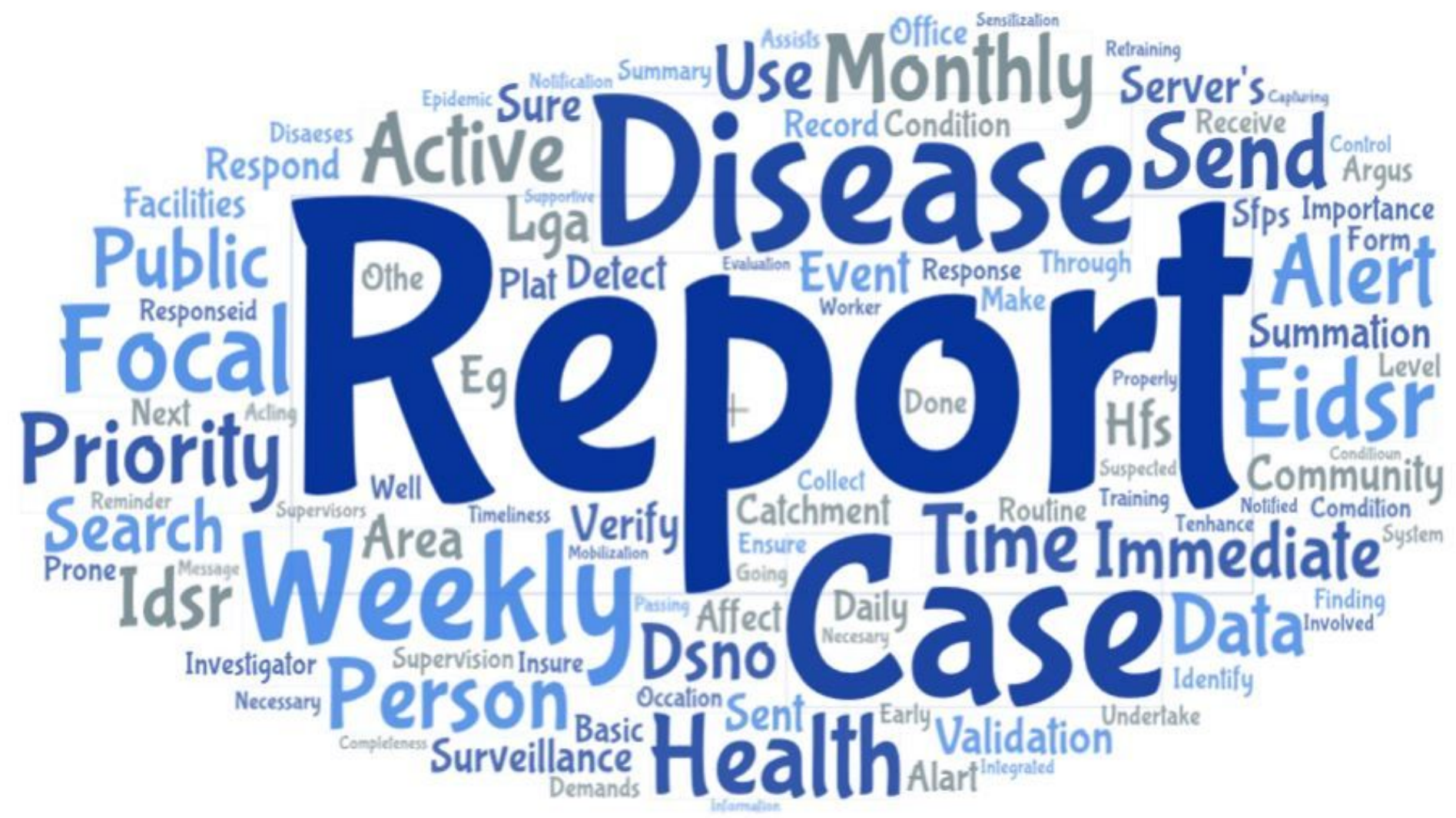

Figure 2

Word cloud of the health facility respondents' view of their role in eIDSR

\section{Supplementary Files}

This is a list of supplementary files associated with this preprint. Click to download.

- QuestionairesforstakeholdersatLGAandstatelevels.pdf

- Questionairesforrespondentsathealthfacility.pdf 